\title{
The Propagation Losses of Cold Deposited Zinc Sulfide Waveguides
}

\author{
Saafie Salleh", a, M. N. Dalimin ${ }^{2, b}$ and H. N. Rutt ${ }^{3, c}$ \\ ${ }^{1}$ School of Science and Technolgy, Universiti Malaysia Sabah, \\ 88502 Kota Kinabalu, Sabah, Malaysia \\ ${ }^{2}$ The Vice-Chancellor Office, Universiti Tun Hussein Onn Malaysia, \\ 86400 Batu Pahat, Johor, Malaysia \\ ${ }^{3}$ School of Electronics and Computer Science, University of Southampton, \\ SO17 1BJ Southampton, United Kingdom \\ asaafie@ums.edu.my, bnoh@uthm.edu.my, chnr@ecs.soton.ac.uk.
}

Keywords: Cold deposition, waveguide, zinc sulfide, propagation loss.

\begin{abstract}
Zinc sulfide ( $\mathrm{ZnS}$ ) waveguides with the thickness of $0.5 \mu \mathrm{m}$ have been deposited onto oxidized silicon wafer substrates at cold temperature $\left(\mathrm{T}_{\text {cold }}=-50^{\circ} \mathrm{C}\right)$ and ambient temperature $\left(\mathrm{T}_{\text {ambient }}=25^{\circ} \mathrm{C}\right)$ by thermal evaporation technique. The propagation losses of $\mathrm{ZnS}$ waveguides were determined by a scattering detection method. The propagation losses of cold deposited $\mathrm{ZnS}$ waveguide were $20.41,11.35,3.51$ and $2.30 \mathrm{~dB} / \mathrm{cm}$ measured the wavelengths of $633,986,1305$ and $1540 \mathrm{~nm}$, respectively. Where as, the propagation losses of ambient deposited $\mathrm{ZnS}$ waveguide were $131.50,47.99,4.43$ and $2.74 \mathrm{~dB} / \mathrm{cm}$ measured the wavelengths of $633,986,1305$ and 1540 $\mathrm{nm}$, respectively. The propagation loss of the cold deposited $\mathrm{ZnS}$ waveguide was dominated by surface scattering whereas the propagation loss of the ambient deposited $\mathrm{ZnS}$ waveguide was dominated by bulk scattering.
\end{abstract}

\section{Introduction}

This paper discusses the properties of $\mathrm{ZnS}$ planar optical waveguides fabricated by thermal evaporation of $\mathrm{ZnS}$ thin films onto cold substrates. The temperature of the substrate plays a vital role in determining the structure of an amorphous or polycrystalline for the thermally deposited thin films. In general, covalently bonded materials such as semiconductors produced either amorphous structures at low substrate temperatures or polycrystalline structures at higher temperatures or epitaxial single crystal structures under the same conditions of high temperature deposition [1]. $\mathrm{ZnS}$ thin films prepared by thermal evaporation were exhibited waveguide characteristics that are indicated by light power propagation losses [2]. The propagation losses are related to the structure of the waveguides, and in turn are affected by the substrate temperature.

The major causes of propagation losses in deposited waveguides are surface scattering and absorption by the materials. The high loss in polycrystalline $\mathrm{ZnS}$ waveguides are due to the combination of surface scattering and bulk scattering at the crystalline grain boundaries [3]. Therefore, a small grain size is necessary for a reduction of surface roughness and allows a reduction of the scattering [4]. Thermal depositions of dielectrics are well known for fabrication of anti-reflection coatings can also be used to produce $\mathrm{ZnS}$ waveguides. Generally, the propagation losses of $\mathrm{ZnS}$ waveguides fabricated by this method were very high and they are useless. However, the propagation losses of $\mathrm{ZnS}$ thin film waveguides can be reduced when the depositions were done at room or ambient temperature [3] [5] [6]. The propagation loss of thermally deposited $\mathrm{ZnS}$ waveguide was further reduced to a minimum point if the substrate was cooled down to $-50^{\circ} \mathrm{C}$ [7].

There are several sources of optical loss in thin film waveguide such as absorption, leakage, interface scattering, internal (bulk) scattering and surface scattering. Among these sources, bulk scattering and surface scattering are considered the main factors of the waveguide loss. The scattering loss is the sum of the internal scattering and surface scattering due to surface roughness and the total propagation losses of a waveguide were contributed by all sources (Jiwei et al., 2000). 
In this study, the propagation losses of cold deposited $\mathrm{ZnS}$ waveguides are measured with multiplewavelength laser source and the analysis of the wavelength dependence of propagation losses are established.

\section{Sample Preparation}

ZnS Thin Film Deposition. Thin films of $\mathrm{ZnS}$ were deposited using Edwards (Auto 306) thermal evaporation system. The system pressure was monitored with both Penning gauge and Pirani gauge while the foreline pressure was monitored with a Pirani gauge. The system was regularly pumped down to a base pressure of less than $5 \times 10^{-7}$ Torr. The substrate cooling was achieved using a thermoelectrically cooled substrate holder. The cooling process is simply done by setting the appropriate low voltage of the thermoelectric device. The substrate cooler is operated without liquid nitrogen and is stabled at $-50^{\circ} \mathrm{C}[6]$. Cold depositions are performed at the substrate temperature of $-50^{\circ} \mathrm{C}$. Depositiona are also performed at the substrate temperature of $25^{\circ} \mathrm{C}$ for ambient depositions, for the comparison.

Before each deposition, the substrate was blown with hot air $\left(120^{\circ} \mathrm{C}\right.$ to $\left.150^{\circ} \mathrm{C}\right)$ for about 10 minutes. This is to ensure that the substrate surface free from water vapour and dust residuals. During this preheating process, the thermoelectric cooler was in operation $\left(\mathrm{V}_{\mathrm{app}}=3.5\right.$ volts) to prevent high temperature damage on the TEC. By applying this procedure, $\mathrm{ZnS}$ thin film was found to stick better and was very stable on the substrate. Without preheating, $\mathrm{ZnS}$ thin films could be detached easily from the substrate. The source material was $\mathrm{ZnS}$ (pieces, $3-12 \mathrm{~mm}$ ) with the purity was approximately $99.999 \%$. The source material was then filled up in the alumina crucible until approximately three quarter full. Fresh source material was used in every deposition to maintain the purity and stoichiometric consistency. The chamber door was closed and the system was pumped. The liquid nitrogen trap was filled and the system was pumped down until the base pressure is reached.

At this stage, the deposition procedures depend on whether cold deposition or ambient deposition was performed. For cold deposition, the TEC power supply was switched ON and was set up to a voltage of $3.5 \mathrm{~V}$. The cold deposition was carried out when the substrate temperature was stabled at $-50^{\circ} \mathrm{C}$. For the ambient deposition, no substrate cooling was required and the deposition was performed whenever vacuum level was satisfied. The substrate temperature of ambient deposition was measured and was found stabled at about $25^{\circ} \mathrm{C}$. Once the proper deposition settings were adjusted and recorded, the $\mathrm{ZnS}$ source materials was slowly heated up by increase the current of the crucible heater. When the deposition rate of $0.50 \mathrm{~nm} / \mathrm{s}$ was achieved and stabled at $\pm 0.05 \mathrm{~nm} / \mathrm{s}$, the shutter was opened. Depositions were carefully performed using the same parameters until the thickness of $0.50 \mu \mathrm{m}$ is obtained.

\section{Sample Characterizations}

Prism Coupler. A commercial prism coupler supplied by a Metricon Corporation (Model 2010) was used in this study. The Metricon Model 2010 Prism Coupler utilises optical waveguiding techniques to measure both thickness and the refractive index of dielectric films. The film to be measured was brought into contact with the prism base by a coupling head. An He-Ne laser with the line wavelength of $633 \mathrm{~nm}$ was incident the prism base and reflected onto a photodetector.

The incidence angle of the laser beam was varied using a rotary table upon which the prism, $\mathrm{ZnS}$ thin film, coupling head and photodetector were mounted. This technique involves the measurement of angles of incident light and the intensity of reflected light by the base of prism. Measurements are made using a computer driven rotary table which varies the incident angle and locates the propagation modes of the film.

At certain angles, photons violate the total internal reflection criterion and tunnel from the prism base into the film and enter into optical propagation modes, causing a sharp drop in the intensity of light striking the photodetector. The angular location of the modes depends only on the film 
thickness and refractive index. The thickness and refractive index of the film are therefore, can be calculated from the measured angles [10].

Propagation Loss Measurement. The scattering detection method was used to measure the power loss of the propagated light in waveguide. The light was coupled into the waveguide using the prism coupler. At the point of propagation mode, the light streak was observed due to the scattering of the light. The intensity of the scattered light was measured along the length of the light streak. This method was a non-destructive and applicable to many waveguides that can be coupled by prism. The optical propagation loss is obtained by measuring the scattered light from the transmitted light beam as a function of the propagation distance [11].

The propagation loss is calculated using the values of the light intensities measured by the photodetector. Assuming the scattering in the films is uniform, the intensity $\mathrm{I}(\mathrm{x})$ of the guided mode is therefore proportional to the scattering intensity $\mathrm{I}_{\mathrm{sc}}(\mathrm{X})$ at the same position, and the propagation loss is [8]

$$
\alpha=\frac{10 \log \left[I_{s c}(X) / I_{s c}(0)\right]}{X}(\mathrm{~dB} / \mathrm{cm})
$$

The probe angle and the distance from the waveguide are maintained constant, and the probe end is moved in proximity to the waveguide to scattering intensities versus position plot, where the loss is extracted. The standard system of the prism coupler operates with only $\mathrm{HeNe}$ laser with the wavelength of $633 \mathrm{~nm}$. Three diode lasers with the emission wavelengths of $986 \mathrm{~nm}, 1305 \mathrm{~nm}$ and $1540 \mathrm{~nm}$ were coupled into the prism coupler for multiple-wavelength measurements.

\section{Results and Discussion}

The Propagation Modes. Figure 1 show the measurements of propagation modes of $0.50 \mu \mathrm{m}$ thick $\mathrm{ZnS}$ waveguide sample. The $\mathrm{X}$-axis values in these figures were the step number of the turntable motor for varying incident angles into the prism. It is clear that the $\mathrm{ZnS}$ waveguide sample have three propagation modes.

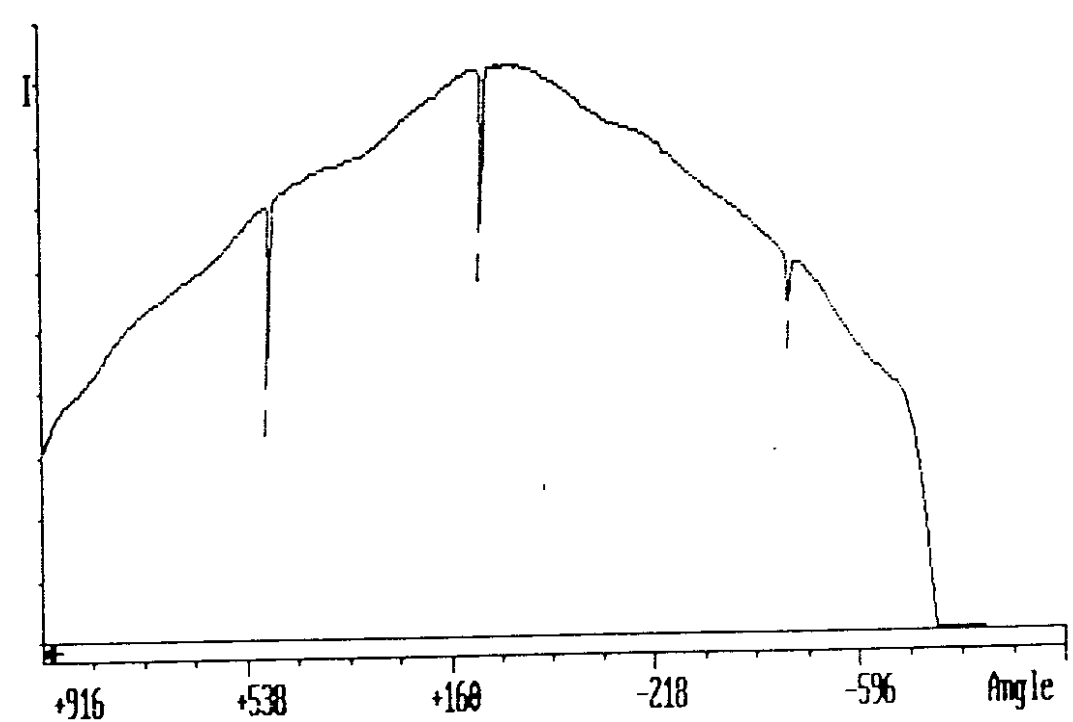

Figure 1: Propagation modes of the $\mathrm{ZnS}$ waveguide sample with the thickness of $0.50 \mu \mathrm{m}$.

The Propagation Losses. The results of the propagation losses measurement of both cold deposited and ambient deposited $\mathrm{ZnS}$ waveguides are tabled in Table 1. Propagation losses of the 
cold deposited $\mathrm{ZnS}$ waveguide were 20.41, $11.35,3.51$ and $2.30 \mathrm{~dB} / \mathrm{cm}$ measured at the wavelengths of 633, 986, 1305 and $1540 \mathrm{~nm}$, respectively. Whereas, propagation losses of $\mathrm{ZnS}$ waveguides the ambient deposited $\mathrm{ZnS}$ waveguide were $131.50,47.99,4.43$ and $2.74 \mathrm{~dB} / \mathrm{cm}$ measured at the wavelengths of 633, 986, 1305 and $1540 \mathrm{~nm}$, respectively.

Table 1 Propagation losses of $\mathrm{ZnS}$ waveguides (measured at $\mathrm{TE}_{0}$ mode).

\begin{tabular}{|c|c|c|}
\hline \multirow{2}{*}{$\begin{array}{c}\text { Wavelength } \\
{[\mathrm{nm}]}\end{array}$} & \multicolumn{2}{|c|}{$\begin{array}{c}\text { Propagation loss of ZnS waveguides } \\
{[\mathrm{dB} / \mathrm{cm}]}\end{array}$} \\
\cline { 2 - 3 } & $\begin{array}{c}\text { Cold deposited } \\
\text { ZnS waveguide }\end{array}$ & $\begin{array}{l}\text { Ambient deposited } \\
\text { ZnS waveguide }\end{array}$ \\
\hline$\lambda_{1}=633$ & 20.41 & 131.50 \\
\hline$\lambda_{2}=986$ & 11.35 & 47.99 \\
\hline$\lambda_{3}=1305$ & 3.51 & 4.43 \\
\hline$\lambda_{4}=1540$ & 2.30 & 2.74 \\
\hline
\end{tabular}

The propagation losses of the cold deposited $\mathrm{ZnS}$ waveguide were consistently lower (at all wavelengths) than the propagation losses of the ambient deposited $\mathrm{ZnS}$ waveguide. To the best of our knowledge, the values of propagation losses of $\mathrm{ZnS}$ waveguides at the wavelengths beyond visible region (wavelengths of 986, 1305 and $1540 \mathrm{~nm}$ ) are established for the first time. It is obvious that at shorter wavelengths $(633$ and $986 \mathrm{~nm})$, the ambient deposited $\mathrm{ZnS}$ waveguide showed significantly higher loss then that of the cold deposited. At longer wavelengths (1305 nm and $1540 \mathrm{~nm}$ ), the differences in the propagation losses were small. As the wavelength increased, the propagation losses of the ambient deposited waveguide are reduced more rapidly compare to the cold deposited $\mathrm{ZnS}$ waveguide.

The Wavelength Dependence of the Propagation Losses. The wavelength dependence of waveguide propagation loss can provide information on whether volume scattering, surface scattering or combinations of both that cause the losses. Figure 2 show the plots of measured propagation losses of ambient and cold deposited $\mathrm{ZnS}$ waveguides. Power fits using the least square fitting method were done for both curve of the propagation loss. The power fitting of the propagation losses showed $\lambda^{-4.6}$ and $\lambda^{-2.5}$ dependence for the ambient deposited $\mathrm{ZnS}$ waveguide and the cold deposited $\mathrm{ZnS}$ waveguide, respectively. The $\lambda^{-4.6}$ dependence was a sign of bulk scattering or Rayleigh scattering and the $\lambda^{-2.5}$ dependence was a deviation from Rayleigh scattering.

From the curves of the propagation losses in Figure 2, it is suggested that the losses were caused by scattering and not by the absorption within the material. It is known that if the losses were strictly caused by Rayleigh scattering, losses should have exhibited a $\lambda^{-4}$ dependence but the propagation loss of the ambient deposited $\mathrm{ZnS}$ waveguide had a $\lambda^{-4.6}$ dependence. Rayleigh scattering is observed in the case of light waves interacting with grain particles where the grains size smaller than the wavelengths. It is suggested that the crystallite grains formed in the ambient deposited $\mathrm{ZnS}$ waveguide were responsible for this relationship. Small deviation from $\lambda^{-4}$ dependence was expected because of the existence other loss mechanisms or imperfections nature of the waveguide. The propagation losses of the ambient deposited $\mathrm{ZnS}$ waveguide were dominated by scattering from the bulk of the $\mathrm{ZnS}$ films and not from the surface scattering. 


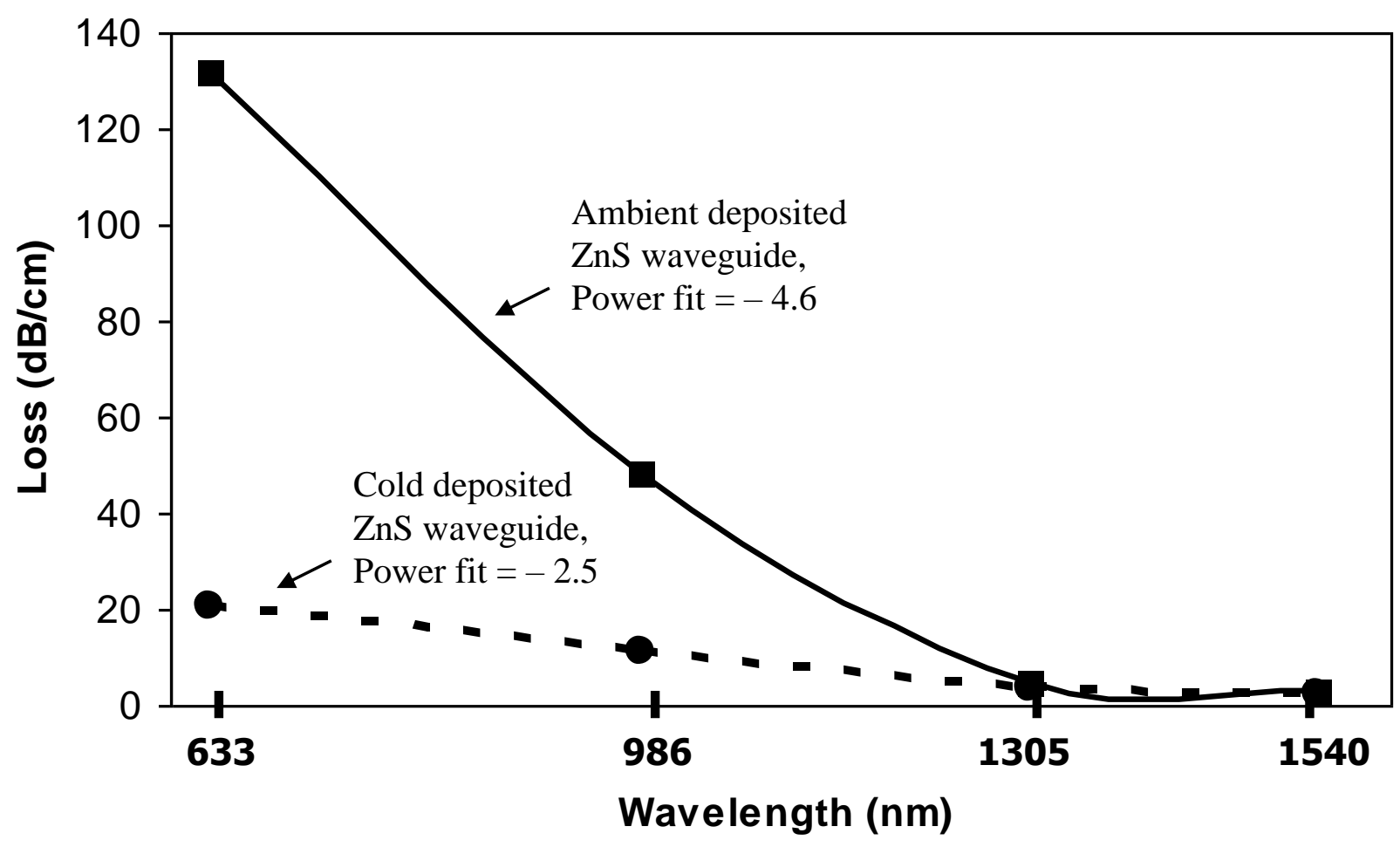

Figure 2: Propagation loss versus wavelength for cold and ambient deposited $\mathrm{ZnS}$ waveguides.

Large deviation from $\lambda^{-4}$ dependence for the cold deposited $\mathrm{ZnS}$ waveguides was expected because amorphous $\mathrm{ZnS}$ waveguide responds in a different manner from the ambient deposited $\mathrm{ZnS}$ waveguide. There is no interaction or minor interaction between the light waves and the grains. Rayleigh scattering was no longer dominant in this case and the $\lambda^{-2.5}$ dependence was probably due to the surface roughness because majority of the scattering occurred at the surface. The surface roughness of the cold deposited $\mathrm{ZnS}$ waveguide was about three times rougher than the ambient deposited $\mathrm{ZnS}$ waveguide. This result agreed well with the recent study on the surface roughness effects in the low temperature deposited $\mathrm{ZnS}$ thin films. The surface scattering and optical loss were reported to increase when surface roughness was increased [12]. Both experimental and theoretical results show that surface roughness plays a decisive role in the attenuation of propagating light, especially in the submicron range of layer thicknesses [13].

The wavelength dependence of propagation losses analysis indicated that the cold deposited $\mathrm{ZnS}$ waveguide is characterized by surface scattering probably due to surface roughness. Whereas, the ambient deposited $\mathrm{ZnS}$ waveguide is characterized by bulk scattering probably because of the presence of reasonable large grains and grain boundary effects.

\section{Conclusion}

The propagation loss in the cold deposited $\mathrm{ZnS}$ waveguide was lower than the loss in the ambient deposited $\mathrm{ZnS}$ waveguide. The differences in propagation losses of the $\mathrm{ZnS}$ waveguides was large at shorter wavelengths but was small at longer wavelength. The propagation loss cold deposited $\mathrm{ZnS}$ waveguide had a $\lambda^{-2.5}$ dependence of the and the propagation loss of ambient deposited $\mathrm{ZnS}$ waveguide had a $\lambda^{-4.6}$ dependence. The propagation loss of cold deposited $\mathrm{ZnS}$ waveguide was dominated by surface scattering whereas, the propagation loss of the ambient deposited $\mathrm{ZnS}$ waveguide was dominated by bulk scattering from the polycrystalline structure. 


\section{References}

[1] J.A. Thornton, Physical vapour deposition, in G. E. McGuire (ed). Semiconductor Materials and Process Technology Handbook, Noyes Publications, New Jersey, (1988).

[2] A.A.J Al-Douri, The influence of substrate temperature on the optical losses of $\mathrm{ZnS}$ film, Journal of Vacuum Science and Technology A, Vol. 4 No. 6 (1986), 2477-2481.

[3] M.D. Himel and T.C. Kimble, Determination of volume and surface contributions to the total attenuation in ZnS waveguides, Applied Optics, Vol. 32 No. 18 (1993), 3306-3311.

[4] B. Wong, P.E. Jessop and A.H. Kitai, Pockel's effect in polycrystalline ZnS planar waveguides, Journal of Applied Physics Vol.70 No. 3 (1991), 1180-1184.

[5] M. D. Himel and U. J Gibson, Measurement of planar waveguide losses using a coherent fiber bundle. Applied Optics, Vol. 25, No. 23 (1986), 4413-4416.

[6] M. D. Himel and T. C. Kimble, Determination of volume and surface contributions to the total attenuation in ZnS waveguides. Applied Optics, Vol. 32, No. 18, (1993), 3306-3311.

[7] J.A. Ruffner, M.D. Himel, V. Mizrahi, G.I. Stegeman and U.J. Gibson, Effects of low substrate temperature and ion assisted deposition on composition, optical properties and stress of $\mathrm{ZnS}$ films. Applied Optics, Vol.28 No. 24 (1989) 209-5214.

[8] Z. Jiwei, Y. Xi and Z. Linagying, Characterization and optical propagation loss of sol-gel derived TiO2/SiO2 films, J. Phys. D: Appl. Phys, Vol.33 (2000), 3013-3017.

[9] Saafie Salleh, Abdullah Chik, M.N. Dalimin and H.N. Rutt, Propagation mode of cold evaporation zinc sulfide planar waveguides, Borneo Science, Vol. 17 (2005), 55-61.

[10] X. J. Zhang, X. Z. Fan, H. T. Wang, J. L. He and N. B. Ming, Simple and efficient technique for evaluating the optical losses from surface scattering and volume attenuation in a thin film. Optics Express, Vol, 10, No. 25, (2002), 1485-1490.

[11]H. Nishihara, M. Haruna and T. Suhara, Optical Integrated Circuits, McGraw Hill Book Company, New York, (1989).

[12]X. Wu, F. Lai, L. Lin, J. Lv, B. Zhuang, Q. Yan and Z. Huang, Optical inhomogeneity of ZnS films deposited by thermal evaporation. Applied Surface Science, Vol. 254, No. 20, (2008), 6455-6460.

[13]I. Szendro, Zs. Puskas, K. Somogyi, and K. Erdelyi, Surface scattering optical loss measurements in thin oxide planar waveguide layers. Thin Solids Films, Vol. 516, (2008), 8215-8218. 